\title{
Long-term supplementation with selenate and selenomethionine: urinary excretion by New Zealand women
}

\author{
BY MARION F. ROBINSON ${ }^{1}$, CHRISTINE D. THOMSON ${ }^{1}$, CHRISTOPHER $^{2}$ \\ P. JENKINSON ${ }^{2}$, GU LUZHEN ${ }^{3}$ AND PHILIP D. WHANGER ${ }^{4}$ \\ ${ }^{1}$ Department of Human Nutrition, University of Otago, PO Box 56, Dunedin, New Zealand \\ ${ }^{2}$ Mental Retardation Research Center, Center for Health Science, 760 Westwood Plaza, University of \\ California Los Angeles, Los Angeles, CA 90024-1759, USA \\ ${ }^{3}$ Institute of Nutrition and Food Hygiene, Chinese Academy of Preventive Medicine, 29 Nan Wei Road, \\ Beijing, People's Republic of China \\ ${ }^{4}$ Department of Agricultural Chemistry, Oregon State University, Corvallis, Oregon 97331-6502, USA
}

(Received 7 May 1996 - Revised 23 July 1996 - Accepted 14 August 1996)

\begin{abstract}
Thirty-six New Zealand women aged between 18 and 23 years received daily for 32 weeks, $200 \mu g$ Se as Se-enriched yeast (selenomethionine, SeMet), or brewer's yeast mixed with selenate, or no added Se (placebo) in a double-blind trial. Mean daily Se excretion increased with both supplements; the selenate group excreted more than the SeMet group, 123 v. $66 \mu \mathrm{g} / \mathrm{d}$ respectively at week 2 , equivalent to $57 \mathrm{v.27} \%$ of the dose. Thereafter Se output increased for the SeMet group reaching a plateau at about $100 \mu \mathrm{g} / \mathrm{d}$ at week 16, when plasma Se had also plateaued at $190 \mathrm{ng} / \mathrm{ml}$. The selenate group had reached an earlier plateau of $110 \mathrm{ng} \mathrm{Se} / \mathrm{ml}$ at week 7. There was a close relationship between $24 \mathrm{~h}$ urine and plasma Se for the SeMet group but not for the selenate group. Renal plasma clearances showed two distinctly different responses; the clearance of $0.4 \mathrm{ml} / \mathrm{min}$ reached by the SeMet group at week 2 plateaued as plasma Se increased almost 2-fold; whereas for the selenate group the clearance varied between 0.8 and $1.1 \mathrm{ml} / \mathrm{min}$ whilst plasma Se remained almost constant at $110 \mathrm{ng} / \mathrm{ml}$. Previous studies, also of $200 \mu \mathrm{gSe} / \mathrm{d}$ as Se-rich bread, in New Zealand (NZ) and elsewhere showed similar responses to Se-yeast; the selenite response was intermediate between selenate and Se-yeast (SeMet). The full significance of these studies awaits identification of Se components in plasma, glomerular filtrate and urine; meanwhile renal clearances serve as a pointer to changes in the distribution of Se-containing fractions in the plasma. Trimethylselenonium was detected in basal urines, and was a minor component in urines of supplemented NZ subjects at about $1 \%$ of the total Se.
\end{abstract}

Selenium: Urinary excretion: Renal plasma clearance: Women

The question of which is the preferred form of Se to raise the Se status of individual persons or of a community continues to challenge workers around the world. Selenite, selenate, selenomethionine, Se-enriched yeast and food Se are effective in short-term Se studies, but there is concern about their use for long-term supplementation, and also about which is the most appropriate criterion for assessing Se status and for alerting to possible toxic effects. The problem is complicated by the scarcity of information about the dietary forms, functions, metabolism and excretion of Se. Because of concern about long-term effects of prolonged supplementation with selenite, attention is now being directed towards selenate as a Se supplement and also to its use as an agricultural fertilizer with effects on 
both animal and plant foods, as in Finland (Varo et al. 1988). Selenomethionine (SeMet), which is the predominant form in both Se-enriched yeast and Se-rich wheat grown on Serich soils, raises blood Se levels more than the inorganic forms and continues to be used as a Se supplement by self-dosers.

We have been seeking to compare the long-term effects of selenate and SeMet on Se metabolism in blood and urine. The response in Se and glutathione peroxidase activity ( $E C$ 1.11.1.9; GSHPx) in blood components has been reported (Thomson et al. 1993), as has the Se distribution in blood fractions (Butler et al. 1991). The present study was designed to compare the effects of supplementation with these two forms on urinary excretion of Se. We had noted that New Zealanders and also the Chinese in Keshan disease areas (Luo et al. 1985) excreted a smaller proportion of the Se presented to their kidneys, i.e. they had lower renal plasma clearances, than North Americans (Robinson et al. 1985). A preliminary report including the response in excretion of trimethylselenonium (TMSe) a Se urinary metabolite, has been presented (Robinson et al. 1989). We now suggest that measurements of the renal plasma clearance of Se may help to clarify the distribution of plasma Se between different fractions.

\section{METHODS}

Thirty-six women resident in Dunedin, New Zealand, and aged 18-23 years participated in a double-blind supplementation study for 32 weeks in 1987. The subjects were randomly assigned to three groups and received daily tablets containing $200 \mu \mathrm{g}$ Se as selenate mixed with brewer's yeast (selenate group), as Se-enriched yeast (SeMet group), or as plain brewer's yeast with no added Se (placebo; $<1 \mu \mathrm{g} \mathrm{Se/tablet).} \mathrm{The} \mathrm{tablets} \mathrm{were}$ manufactured by Vita Tech International, Inc., Tustin, CA, USA and supplied by Nutrition 21 (San Diego, CA, USA). The majority of the Se in the Se-enriched yeast (Se-yeast) supplied by this company has been shown to be in the form of SeMet (Beilstein \& Whanger, 1986). Each subject filled in a brief questionnaire giving details of residency, dietary habits, nutrient supplementation and other information which might influence Se status. The subjects were requested not to eat Se-rich foods, such as fish, liver, kidney or brazil nuts during the $2 \mathrm{~d}$ before the time that urine collections and blood samples were taken. Informed consent was obtained from all subjects, and the study was approved by the ethical committee of the Otago Area Health Board.

Blood and $24 \mathrm{~h}$ urine collections were made on the day before supplementation commenced (week 0), at 2 and 4 weeks and monthly for a further 28 weeks. The blood samples were drawn, separated into plasma and other components, analysed, or stored awaiting later analysis as described previously (Butler et al. 1991; Thomson et al. 1993).

The $24 \mathrm{~h}$ urine samples were collected and stored as described previously (Thomson et al. 1978). The completeness of urine collections was checked from $24 \mathrm{~h}$ creatinine excretions, and five subjects were excluded because their creatinine excretion was $7 \mathrm{mmol} /$ d or less on more than two occasions. Creatinine was measured using the picric acid method (Clarke, 1961) adapted for an auto-analyser.

Total Se was determined in individual urine samples and also in pooled group urines for each stage by the automated fluorimetric method (Brown \& Watkinson, 1977). Sensitivity and sample reproducibility of the method were $0.1 \mu \mathrm{g} / \mathrm{l}$ and SD $2.5 \%$ within the range of $0-100 \mu \mathrm{g} / 1$ (Thomson et al. 1982). Analysis of the National Bureau of Standards (Gaithersburg, MD, USA) reference material no. 1577, bovine liver, gave a value of 1.11 $\mu \mathrm{g} \mathrm{Se} / \mathrm{g}$ (certified value $1.09 \pm 0.10 \mu \mathrm{g} / \mathrm{g}$ ). 
Samples of urines were pooled before the five subjects were excluded; there was excellent agreement between the Se contents of the pooled urine and the mean for the individual urines for each group at each stage.

TMSe was determined in pooled group urines for weeks $0,2,4$, and then 4-weekly, by a dual column ion-exchange method, a modification of the method of Nahapetian et al. (1984). The very low concentration of TMSe in normal New Zealand (NZ) urines limited our choice of method because of the large sample size needed for the reineckate method and the problem of adequate desalting for the HPLC technique (Kraus et al. 1985). Good agreement was obtained between HPLC and the chosen dual column techniques for TMSerich urines collected from a subject after ingesting TMSe (144 ng Se/ml; $139 \mathrm{ng} \mathrm{Se} / \mathrm{ml}$ urine respectively). Replicate analyses of urines from supplemented subjects gave CV of 10-20\%; mean recoveries of standards and TMSe added to urines varied between 81 and $94 \%$.

Renal plasma Se clearances $(\mathrm{ml} / \mathrm{min}$ ) were calculated by the conventional formula (Robinson et al. 1985) using concentrations of Se in plasma and the amounts of Se excreted in the urine in $24 \mathrm{~h}$ :

$$
\mathrm{C}_{\mathrm{Se}}=\frac{(\mathrm{Se})_{\mathrm{u}} \cdot \mathrm{V}}{(\mathrm{Se})_{\mathrm{p}}}
$$

where $(\mathrm{Se})_{\mathrm{u}}$ and $(\mathrm{Se})_{\mathrm{p}}$ are Se concentrations in urine and plasma, necessarily expressed in the same units, and $\mathrm{V}$ is the rate of production of urine in $\mathrm{ml} / \mathrm{min}$. The numerator $(\mathrm{Se})_{\mathrm{u}} \cdot \mathrm{V}$ is the amount of Se excreted in the urine in $1 \mathrm{~min}$.

\section{Statistical analysis}

Differences among groups for urinary Se excretion, plasma Se and renal clearances at each time point were calculated using ANOVA and Student's $t$ test after log transformation. Changes with time within each group were calculated using ANOVA for repeated measures after log transformation (Statview, $\mathrm{SE}+$ Graphics ${ }^{\circ}$, version 1.03, Abacus Concepts Inc., Berkeley, CA, USA).

\section{RESULTS}

Baseline information about the subjects is given in Table 1, including height, weight, BMI, plasma Se concentrations, $24 \mathrm{~h}$ urinary excretions of Se and creatinine, and renal plasma clearances of Se. Values did not differ among the three groups. However a subject in the selenate group had mistakenly eaten a generous serving of fish on the day of urine collection for week 0 resulting in a $24 \mathrm{~h}$ excretion of $88 \mu \mathrm{g} \mathrm{Se} / \mathrm{d}$ and a group mean of 17.6 (SD 2.5) $\mu \mathrm{g} \mathrm{Se} / \mathrm{d}(n$ 10); without it the mean became 9.4 (SD 4.1) $\mu \mathrm{g} \mathrm{Se/d} \mathrm{(n} \mathrm{9),} \mathrm{close} \mathrm{to} \mathrm{the}$ means for the other two groups. No differences in plasma Se and urinary Se outputs were detected for the five subjects who described themselves as semi-vegetarians or another two who were lacto-ovo-vegetarians.

Mean daily Se excretions increased with both supplements $(P<0.0001)$ and no changes were seen in the placebo group (Fig. 1). At each stage the SEM was greater for the selenate than for the SeMet group and often markedly so. Examination of the individual Se urinary outputs showed that six selenate subjects had excretions over $200 \mu \mathrm{g} \mathrm{Se} / \mathrm{d}$ (megaurines) with two over $300 \mu \mathrm{g} \mathrm{Se} / \mathrm{d}$ at week 25 . This possibly reflected irregularities in taking the supplement, e.g. late in the evenings instead of the prescribed one capsule in the morning. On the other hand lesser excretions, about $40 \mu \mathrm{g}$ Se/d occurred on seven 
Table 1. Baseline values for plasma selenium concentrations and urinary excretions of selenium and creatinine in New Zealand women

(Mean values and standard deviations)

\begin{tabular}{|c|c|c|c|c|c|c|}
\hline \multirow[t]{2}{*}{ Group*... } & \multicolumn{2}{|c|}{$\begin{array}{c}\text { Selenate } \\
(n \text { 10) }\end{array}$} & \multicolumn{2}{|c|}{$\begin{array}{l}\text { SeMet } \\
(n \text { 12) }\end{array}$} & \multicolumn{2}{|c|}{$\begin{array}{c}\text { Placebo } \\
\text { (n 19) }\end{array}$} \\
\hline & Mean & SD & Mean & SD & Mean & SD \\
\hline Age (years) & 21 & 1 & 21 & 1 & 21 & 1 \\
\hline Height (m) & 1.65 & 0.04 & 1.66 & 0.06 & 1.67 & 0.08 \\
\hline Weight (kg) & 62 & 7 & 59 & 4 & 62 & 6 \\
\hline $\mathrm{BMI}\left(\mathrm{kg} / \mathrm{m}^{2}\right)$ & 22 & 1.7 & $21 \cdot 4$ & 1.2 & 22 & $2 \cdot 0$ \\
\hline Plasma Se (ng/ml) & 52 & 7 & 53 & 5 & 56 & 6 \\
\hline Urine $\mathrm{Se}(\mu \mathrm{g} / \mathrm{d})$ & 9.4 & $4 \cdot 1$ & $10 \cdot 9$ & 2.9 & $11 \cdot 6$ & $4 \cdot 2$ \\
\hline Creatinine $(\mathrm{mmol} / \mathrm{d})$ & 9.4 & $3 \cdot 2$ & $10 \cdot 2$ & 1.7 & 9.4 & 0.9 \\
\hline Urine Se/creatinine $(\mu \mathrm{g} / \mathrm{mmol})$ & 1.01 & 0.34 & 1.10 & 0.3 & 1.22 & 0.38 \\
\hline Renal plasma clearance of $\mathrm{Se}(\mathrm{ml} / \mathrm{min})$ & 0.13 & 0.06 & 0.14 & 0.04 & 0.13 & 0.04 \\
\hline TMSe $\dagger(\mu \mathrm{g} \mathrm{Se} / \mathrm{d})$ & 0.9 & & 0.3 & & 0.6 & \\
\hline
\end{tabular}

TMSe, trimethylselenonium; SeMet, selenomethionine.

* For details of dietary groups, see p. 552.

† For pooled urines.

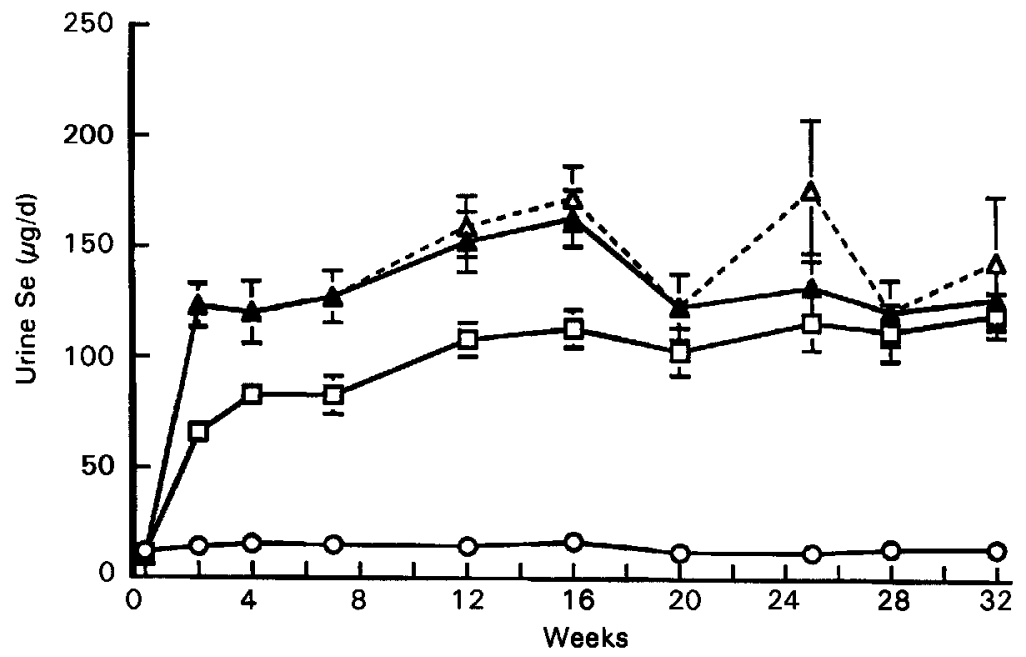

Fig. 1. Urinary selenium excretion by New Zealand women supplemented with selenium either as selenate $(\boldsymbol{\Delta}, n 10)$, or Se-enriched yeast $(\square, n 12)$ or a placebo $(O, n 9)$ for 32 weeks. For details of dietary treatments see p. 552 . Values are means with their standard errors represented by vertical bars; $(\Delta)$ overall mean (weeks 12 and $16, n 9 ;$ weeks 25 and 32 , $n$ 8) for the selenate groups with subjects excreting mega-urines, $>200 \mu \mathrm{g} \mathrm{Se} / \mathrm{d}$, see pp. 553-554.

occasions. The mega-urine outputs were excluded from the excretions for the appropriate selenate group (see Fig. 1). There were no such irregularities for the SeMet group with most falling within the range 50-150 $\mu \mathrm{g}$ Se/d with seven just below and another nine just above this range.

At each stage the selenate group excreted more Se than the SeMet group; at week 2 it accounted for $123 \mu \mathrm{g} \mathrm{Se} / \mathrm{d}$, an increase of $114 \mu \mathrm{g} / \mathrm{d}$, equivalent to about $57 \%$ of the daily $200 \mu \mathrm{g}$ Se dose. This was 2-fold greater than for the SeMet group with a urinary output of 


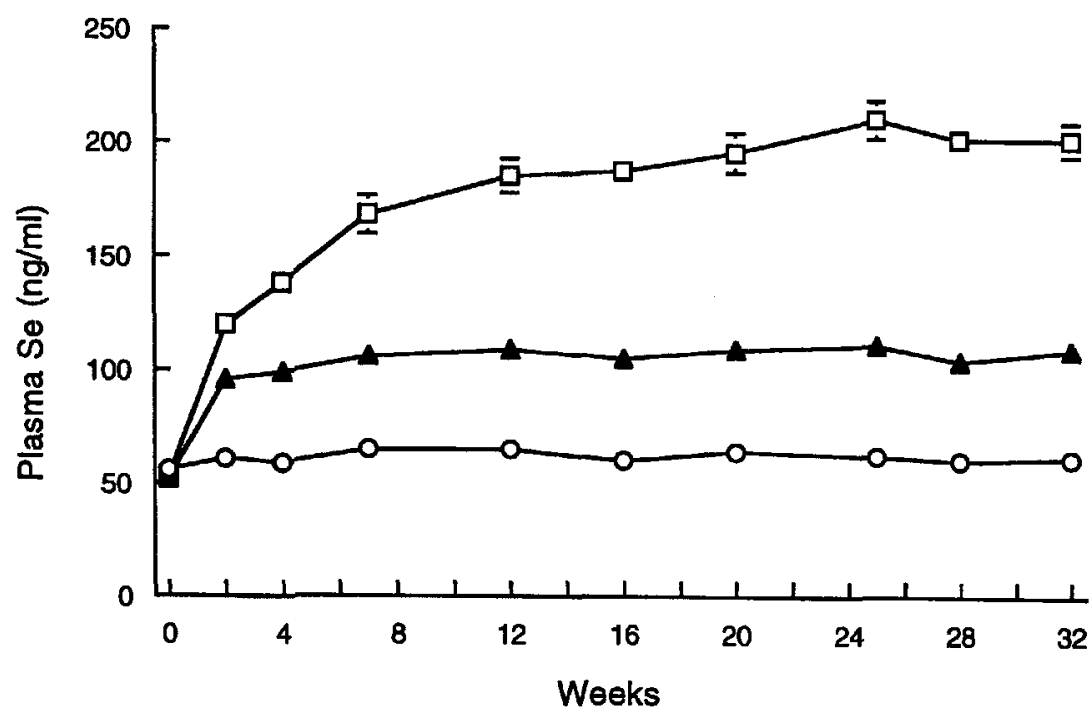

Fig. 2. Selenium concentrations in plasma of New Zealand women supplemented with selenium either as selenate $(\boldsymbol{\Delta}$, $n 10)$, or Se-enriched yeast $(\square, n 12)$, or a placebo $(O, n 9)$ for 32 weeks. For details of dietary treatment see p. 552. Values are means and their standard errors represented by vertical bars.

$66 \mu \mathrm{g} / \mathrm{d}$, about $27 \%$ of the dose. Thereafter the urinary output of the SeMet group continued to rise, reaching a plateau at about $110 \mu \mathrm{g} \mathrm{Se} / \mathrm{d}$ at week 16 , and remained a little less than the corresponding selenate outputs for the later stages of the study. Significant differences in mean excretions were apparent among the three groups from week 2 $(P<0.0001)$, but the differences between the selenate and the SeMet groups were significant at week $2(P<0.001)$ and from weeks 7 to 16 only $(P<0.02)$.

As pointed out previously (Thomson et al. 1993) plasma Se in the selenate group plateaued at about 7 weeks at $110 \mathrm{ng} / \mathrm{ml}$ (Fig. 2) but rose further in the SeMet group reaching a plateau of $190 \mathrm{ng} / \mathrm{ml}$ at week 16, when urine Se outputs for the SeMet group had also reached a plateau. Significant differences in mean plasma concentrations were apparent among the three groups from week $2(P=0.001)$, and at the end of the supplementation period plasma Se in the SeMet group was nearly 2 -fold greater than in the selenate group. A close relationship was observed for the SeMet group between $24 \mathrm{~h}$ urine Se excretion and plasma Se concentration $(r 0.96 ; P<0.001)$ but not for the selenate group (Fig. 3).

\section{Renal plasma clearances}

Renal plasma clearance brings together the changes in plasma Se and urinary Se, which had both increased during the first 2 weeks of supplementation, to reach a plateau at about $0.4 \mathrm{ml} / \mathrm{min}$ for the SeMet group, but to over twice this value for the selenate group, varying between 0.8 and $1.1 \mathrm{ml} / \mathrm{min}$ (excluding the mega-urines) whereas plasma Se remained almost constant. Differences between groups for renal plasma clearances were significant $(P<0.0001)$. These two distinctly different responses are shown in Fig. 4 together with the responses from our earlier studies with daily supplements also of $200 \mu \mathrm{g} \mathrm{Se} / \mathrm{d}$ taken as selenite for 4 weeks (Robinson, 1988; Thomson et al. 1988) and as Se-rich wheat bread for 8 weeks (Robinson et al. 1985; Thomson et al. 1985). Not surprisingly since SeMet is the major Se form in high-Se wheat, the response to high-Se bread resembled strongly the response to Se-yeast, with renal clearance of about $0.5 \mathrm{ml} / \mathrm{min}$, and plasma Se reaching 166 


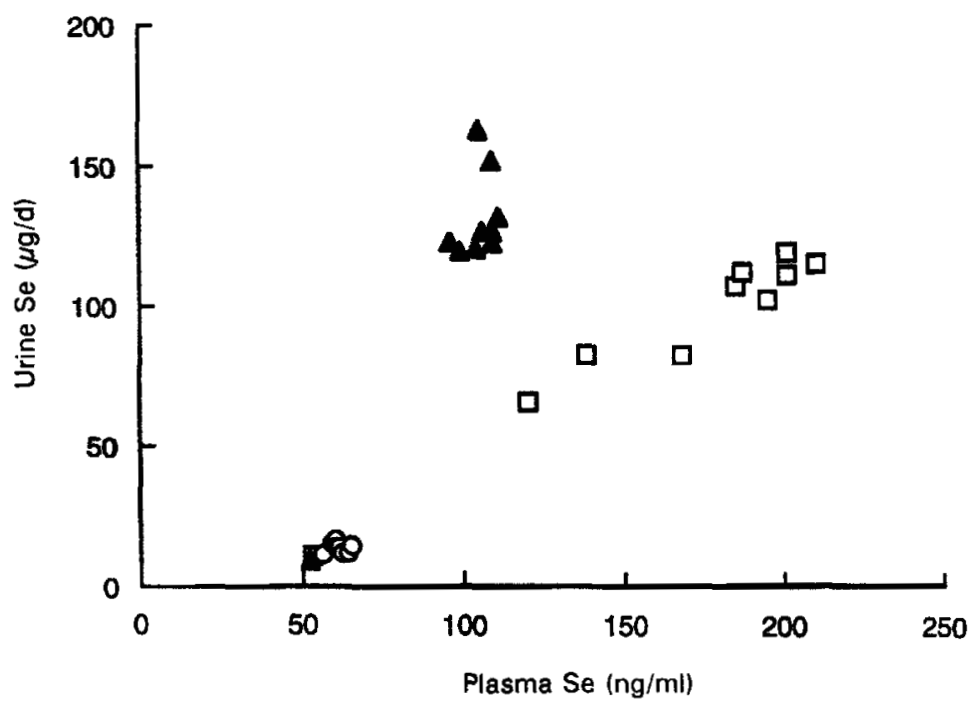

Fig. 3. Relationship between mean urinary excretion of selenium and mean plasma selenium concentration of New Zealand women supplemented with selenium either as selenate $(\boldsymbol{A})$, or Se-enriched yeast $(\square])$, or a placebo $(O)$ for 32 weeks. For details of dietary treatment see p. 552.

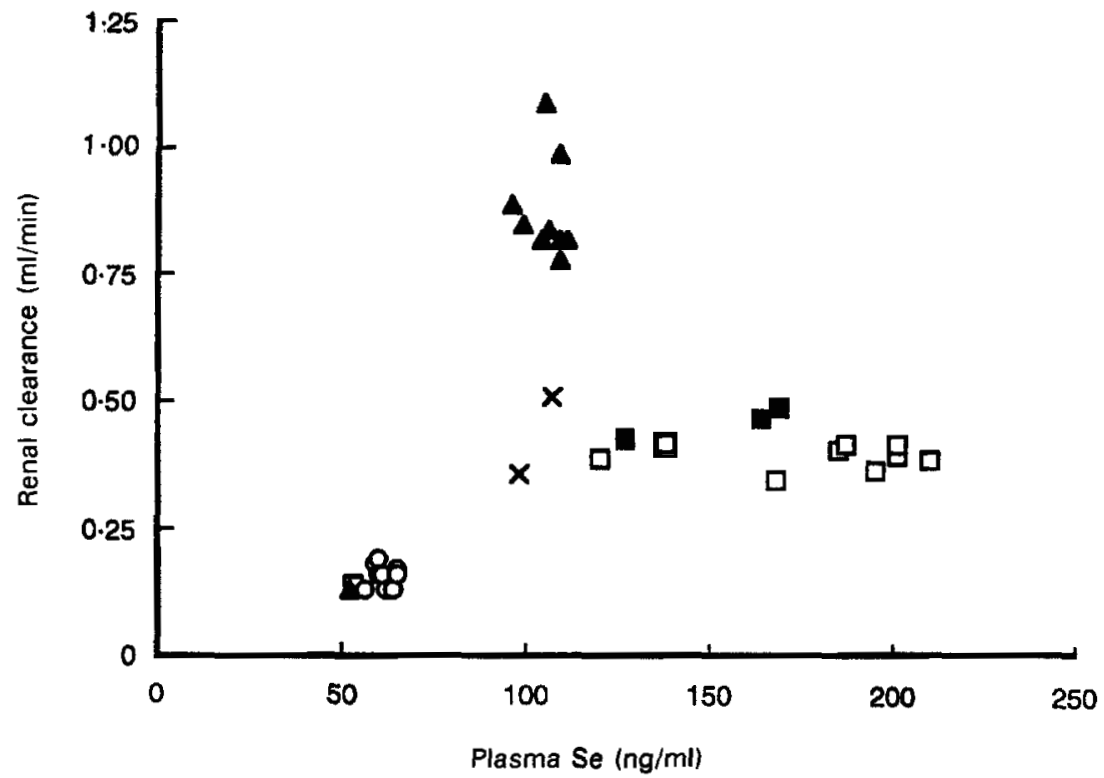

Fig. 4. Relationship between mean renal plasma clearance and mean plasma selenium concentration of New Zealand women supplemented with $200 \mu \mathrm{g}$ Se/d either as Se-enriched yeast ( $\square$ ), or high-Se wheat bread ( $\mathrm{G})$, or selenate (A), or selenite $(x)$, or a placebo $(O)$. For details of dietary treatment, see p. 552. 
ng Se/ml. On the other hand selenite resembled selenate in its plasma response but with only half its renal clearance at $0.5 \mathrm{ml} / \mathrm{min}$.

\section{Trimethylselenonium excretion}

Urinary TMSe in the baseline urines was close to the lower limit of sensitivity of the method and appeared to increase with supplementation (Table 2). TMSe output was a little greater for the selenate group than for the SeMet group at each stage of supplementation; expressed as a proportion of total Se excretion, TMSe/total Se fell from 3-5\% to about $1 \%$ and remained there throughout the study.

\section{DISCUSSION}

We have again exploited the NZ situation with its low Se status to compare the responses of Dunedin women to increasing the intake with supplements of $200 \mu \mathrm{g}$ Se/d supplied in the four prime forms of Se as: selenate, SeMet (or Se-enriched yeast in the present study), selenite and food-Se (as high-Se wheat bread in earlier studies).

The urinary output yields information about how the supplement is handled, but its reliability is limited by the completeness of $24 \mathrm{~h}$ urine collections. Although none of the subjects in the present study reported errors it was considered from their creatinine excretion that five subjects should be excluded (Bingham \& Cummings, 1985). The mean creatinine excretion for each of these subjects was $8 \mathrm{mmol} / \mathrm{d}$ or less, with $\mathrm{CV}>30 \%$ (Webster \& Garrow, 1985; Mills \& Hocken, 1986).

Our earlier studies yielded background information about the response to supplements varying between $100 \mu \mathrm{g}$ and $1 \mathrm{mg}$ Se in the four forms (Robinson, 1988). The supplements had been given as a single dose or daily for periods of 4-17 weeks, whereas in the present study supplementation continued for 32 weeks. Single-supplement studies with $1 \mathrm{mg}$ Se demonstrated the differences in handling Se as selenite, selenate, and SeMet (Thomson \& Robinson, 1986). Selenate-Se was more readily absorbed than selenite-Se, reaching a peak within $3 \mathrm{~h}$, and with about $70 \%$ of the amount of Se ingested rapidly excreted within $24 \mathrm{~h}$. Peak excretion was reached $3 \mathrm{~h}$ later for selenite-Se with about $20 \%$ recovered within the day. Sandholm (1973) and Burk (1974) have shown that selenite is quickly taken up by

Table 2. Trimethylselenonium (TMSe) excretion ( $\mu \mathrm{g} \mathrm{Se/d)}$ in pooled urines of New Zealand women at each stage during daily supplementation with $200 \mu \mathrm{g}$ Se as selenate or Se-enriched yeast (SeMet) or a placebo for 32 weeks*

\begin{tabular}{|c|c|c|c|c|c|c|}
\hline \multirow{2}{*}{$\begin{array}{l}\text { Group... } \\
\text { Weeks }\end{array}$} & \multicolumn{2}{|c|}{$\begin{array}{c}\text { Selenate } \\
(n \text { 13) }\end{array}$} & \multicolumn{2}{|c|}{$\begin{array}{l}\text { SeMet } \\
(n \text { 13) }\end{array}$} & \multicolumn{2}{|c|}{$\begin{array}{c}\text { Placebo } \\
(n \text { 10) }\end{array}$} \\
\hline & $\begin{array}{c}\text { TMSe } \\
(\mu \mathrm{g} \mathrm{Se} / \mathrm{d})\end{array}$ & $\begin{array}{c}\text { TMSe/Se† } \\
(\%)\end{array}$ & $\begin{array}{c}\text { TMSe } \\
(\mu \mathrm{g} \mathrm{Se} / \mathrm{d})\end{array}$ & $\begin{array}{c}\text { TMSe/Se } \dagger \\
\text { (\%) }\end{array}$ & $\begin{array}{c}\text { TMSe } \\
(\mu \mathrm{g} \mathrm{Se} / \mathrm{d})\end{array}$ & $\begin{array}{c}\text { TMSe/Se } \dagger \\
(\%)\end{array}$ \\
\hline $\begin{array}{l}0 \\
2 \\
12-28 \S\end{array}$ & $\begin{array}{c}0.9 \\
1.8 \\
1.9 \\
(1.7-2.3)\end{array}$ & $\begin{array}{c}5 \ddagger \\
1.5 \\
1.4 \\
(1.2-1.5)\end{array}$ & $\begin{array}{c}0.3 \\
0.7 \\
1.3 \\
(0.9-1.9)\end{array}$ & $\begin{array}{c}3 \\
1 \\
1.2 \\
(0.8-1 \cdot 6)\end{array}$ & $\begin{array}{c}0.6 \\
0.9 \\
0.7 \\
(0.6-0.9)\end{array}$ & $\begin{array}{c}5 \\
6 \\
5 \\
(4-6)\end{array}$ \\
\hline
\end{tabular}

* For details of procedure and dietary groups, see p. 552-553.

$\uparrow$ TMSe excretion as proportion of total Se excretion.

$\$$ Pooled urine contained $18 \mu \mathrm{g} \mathrm{Se} / \mathrm{d}$.

$\S$ Mean values and ranges for urines collected from week 12. 
erythrocytes, metabolized and returned to plasma, becoming bound to protein (Sunde, 1990). SeMet-Se was well absorbed but was mainly retained and only about $22 \%$ recovered in the urine. Similar trends were shown in the initial stages of the present studies with about $57 \%$ and $27 \%$ recovered for selenate and SeMet groups respectively. Without knowledge of the urinary Se components it is uncertain how much of the increase in urinary excretion can be related to the Se content of the dose as such, but it is common to express the increase above the baseline urinary excretion as a proportion of the amount of $\mathrm{Se}$ in the dose.

It would have been valuable to identify and determine the proportions of the various inorganic and organic Se components present in the plasma, the glomerular filtrate and the urine after ingestion of these supplements. Our colleagues in Oregon have shown from gel filtration of plasma that those taking SeMet (Se-yeast) revealed two major Se-containing peaks with most of the Se in the second peak (peak IV, albumin) and this increased during the study; whereas for those taking selenate most of the Se went to peak II (selenoprotein P) and the Se content of that peak remained fairly constant (Butler et al. 1991). However in order to understand the mechanism of urinary excretion, more information is needed about the 'free Se components' from these supplements in the plasma, glomerular filtrate and urine, and unfortunately there has been little progress in identifying these (Burk, 1976; Robberecht \& Deelstra, 1984; Janghorbani et al. 1990; Oster \& Prellwitz, 1990; Alaejos \& Romero, 1993). We have established that TMSe is a minor component in the urine of NZ subjects, and amounts to about $1 \%$ of the total Se in the urines of supplemented subjects. This supports the findings of Sun et al. (1987) who found similarly low values for TMSe of about $1 \%$ of the total Se for US residents.

In 1985 we suggested that most of the free SeMet-Se that enters the glomerular filtrate is probably reabsorbed by the proximal tubules, like other amino acids and glucose, by a mechanism shared by methionine (Robinson et al. 1985). Thus SeMet should increase the concentration of Se in the plasma and presumably also in the methionine pool; it should increase the excretion and clearances only in so far as the larger store of SeMet yields more Se to the central pool (Burk, 1986). It is generally considered that SeMet follows some of the methionine metabolic pathways, becoming incorporated into protein in place of methionine and thereby contributes to tissue Se (Levander \& Burk, 1990). Free inorganic Se compounds that enter the glomerular filtrate are less likely to be reabsorbed and should increase rates of excretion and renal clearance rather than plasma Se concentration, as happened with selenate and possibly also with selenite. It was remarkable how in our various dosing trials since 1975 with daily doses of $90-500 \mu \mathrm{g} \mathrm{Se} / \mathrm{d}$ as selenite, and possibly also of selenate, the plasma Se increased only to $100-120 \mathrm{ng} / \mathrm{ml}$ where it remained until dosing ceased. This has also been noted by Alfthan et al. (1991) in their supplementation trials, also with $200 \mu \mathrm{g} \mathrm{Se} / \mathrm{d}$, in 1981 (Levander et al. 1983) and then in 1987 after the Se intake in Finland had been raised by $100 \mu \mathrm{g} / \mathrm{d}$, as the Se contents of both animal and vegetable products were raised by selenate enrichment of fertilizers (Varo $\mathrm{et} \mathrm{al}$. 1988).

The same men were studied in both Finnish trials. The basal plasma Se concentration at $70 \mathrm{ng} / \mathrm{ml}$ in $1981 \mathrm{had}$ increased in 1987 to $106-114 \mathrm{ng} \mathrm{Se} / \mathrm{ml}$, the range for the group means. Selenite, but not selenate, increased the plasma Se to above the placebo to $126 \mathrm{ng}$ $\mathrm{Se} / \mathrm{ml}$, whereas SeMet-Se (Se-yeast) reached $169 \mathrm{ng} / \mathrm{ml}$ at week 11. Trends in urinary excretions were similar for the Finnish and NZ studies, with greatest amounts excreted for selenate groups. The large SEM could indicate some mega-urines amongst these Finnish men, i.e. $>200 \mu \mathrm{g} \mathrm{Se} / \mathrm{d}$ above the baseline output of $64 \mu \mathrm{g} / \mathrm{d}$. We calculated renal plasma clearances from their data and have listed them with the plasma Se in Table 3 together with 
URINARY EXCRETION OF SELENIUM

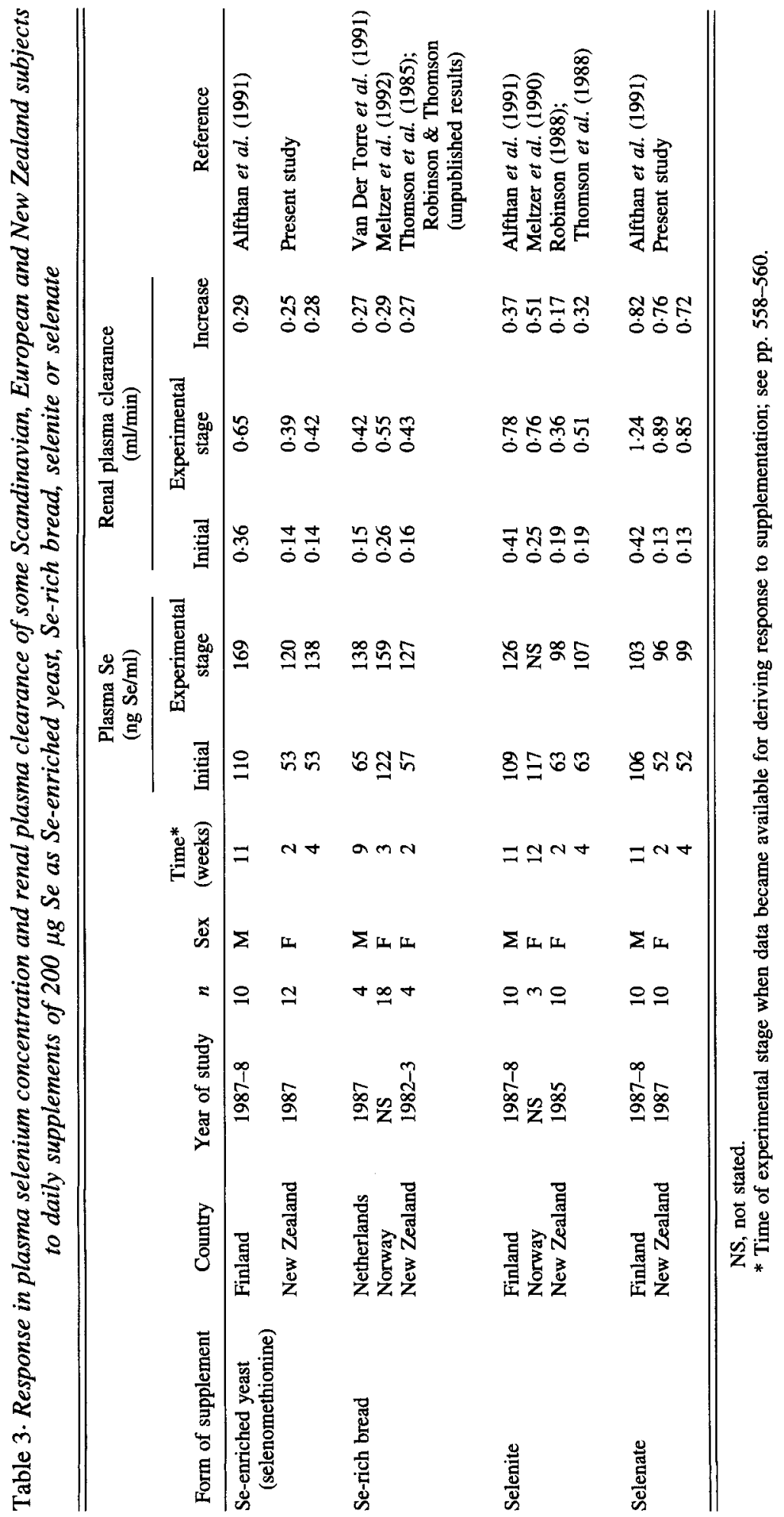


NZ data. Some other groups have also followed the response to supplements of about 200 $\mu \mathrm{g} \mathrm{Se} / \mathrm{d}$ of one or more of the four prime forms of Se supplement and where available their plasma Se and renal plasma clearances are also given in Table 3. Findings for the supplementation response are given for the initial stage and then at the first stage for which renal plasma clearances could be calculated.

It may not be valid to compare the findings at different stages of supplementation for these groups, but it will be recalled that for the NZ subjects two distinct trends in renal plasma clearances seemed to be established early in supplementation for both the organic and the inorganic Se forms. Table 3 shows similar trends in response to each form of supplement despite different baseline plasma concentrations and renal plasma clearances. It is interesting that the baseline data in Table 3 show the same trends of excretion and renal plasma clearance illustrated in Fig. 1 of our earlier paper (Robinson et al. 1985).

For the SeMet studies baseline data for the Finnish subjects were over 2-fold greater than for the NZ subjects, whereas the increases in renal plasma clearances with Se-yeast were almost identical at 0.29 and 0.28 (NZ, week 4) respectively. Likewise for the subjects resident in the Netherlands (Van Der Torre et al. 1991), Norway (Meltzer et al. 1992), and $\mathrm{NZ}$, on supplements of Se-rich bread, the increases in renal plasma clearance were 0.27, 0.29 and 0.27 respectively. It will be noted that for the Norwegian subjects the basal renal plasma clearance was between the Finnish and NZ values even though their plasma Se was greater than the Finnish value.

Of the inorganic supplements, selenate-Se showed the greatest increases in clearance, with the Finnish value a little greater than the NZ value, 0.82 and 0.72 respectively, possibly reflecting the inclusion of some mega-urines. The selenite response was much less, with clearance increases from 0.32 (NZ, week 4) to 0.51 (Norway; Meltzer et al. 1990). The plasma response for both forms reflects the closeness of baseline concentrations to the range of $100-120 \mathrm{ng} \mathrm{Se} / \mathrm{ml}$ attained with the inorganic supplements.

For further understanding of the very different responses to dietary and non-dietary sources of Se, we need to know the identity of the Se compounds in the urine, the glomerular filtrate and the plasma, as well as their role in the metabolism of Se. The renal plasma clearance is the volume of plasma that would have contained the amount of Se transferred to the urine in $1 \mathrm{~min}$. With an average normal renal plasma flow of about 600 $\mathrm{ml} / \mathrm{min}$, a clearance of $1 \mathrm{ml} / \mathrm{min}$ means that $0.17 \%$ of the Se in plasma passing through the kidneys is transferred to the urine. The range of clearances in Fig. 4 therefore indicates that between about $0.03 \%$ and $0.2 \%$ of the plasma Se was being excreted. The clearance axis in effect shows the proportion of the total Se in the plasma that was excreted. When the plasma Se was raised beyond $100 \mathrm{ng} / \mathrm{ml}$ by ingesting Se-yeast (SeMet), the rate of excretion continued to increase (Fig. 3) but the clearance (Fig. 4) did not. Hence, though the rate of excretion increased, the proportion of plasma Se that was excreted remained the same. In contrast, with selenate, the dramatic increase in the rate of excretion after the plasma Se reached $100 \mathrm{ng} / \mathrm{ml}$ occurred with an equally dramatic increase in renal clearance, indicating that a greater proportion of the $\mathrm{Se}$ in the plasma was being transferred into the urine.

Not all Se compounds in the plasma are equally likely to be excreted by the kidney; those which are bound to proteins will not pass into the glomerular filtrate; amino acid forms should be almost completely reabsorbed; free inorganic forms which pass into the glomerular filtrate would be expected to be partially reabsorbed like other anions. (The clearance of chloride, for example, 0.2-2 ml/min according to Koushanpour \& Kriz (1986) is of similar order to that of Se.) The renal plasma clearance results suggest that large doses of selenate (most of which was quickly excreted) increased the proportion of those 
constituents of plasma Se that are freely excreted (presumably free inorganic Se). On the other hand, large doses of SeMet-Se presumably contributed to the central Se pool without much effect on the proportions of the different constituents. Selenite, which showed intermediate behaviour (Fig. 4), is less well absorbed than selenate and is also rapidly taken up into cells before being released to the plasma in protein-bound forms; the modest increase in renal plasma clearance which it produced suggests an intermediate change in the proportions of Se-containing fractions in the plasma. Whilst the separation and identification of these fractions is still lacking, the calculation of renal clearances may, in the mean time, serve to provide a pointer to changes in the distribution of Se-containing fractions in the plasma.

\section{Concluding remarks}

All these studies were designed to show how the various forms of Se are handled, and also to give information about which might be the most appropriate and safe form of Se supplement to raise the Se status of people, should this be considered desirable. The striking similarity of the responses of subjects in different parts of the world from NZ to Northern Europe supports their wide applicability.

The continuing discovery of more and more functions of Se emphasizes its importance as a biological trace element but the need for an increased intake has not yet been established. If supplementation should become necessary we have failed to reveal a significant difference in suitability between selenate and SeMet although they were handled quite differently. Supplementation, if required, could be achieved by consuming more Se-rich foods or indirectly by increasing the Se content of natural foodstuffs (as in Finland where selenized fertilizers have been used), rather than by using chemicals as dietary supplements.

This work was supported by USDA grant no. 86-CRCR-1-2084 and the Medical Research Council of New Zealand. The authors are very grateful to the subjects, to $\mathrm{Mr}$ Peter Huemmer and Ms Trudy Milne for technical assistance and to Professor James Robinson for help in interpreting the results.

\section{REFERENCES}

Alfthan, G., Aro, A., Arvilommi, H. \& Huttunen, J. K. (1991). Selenium metabolism and platelet glutathione peroxidase activity in healthy Finnish men: effects of selenium yeast, selenite, and selenate. American Journal of Clinical Nutrition 53, 120-125.

Alaejos, M. S. \& Romero, C. D. (1993). Urinary selenium concentrations. Clinical Chemistry 39, 2040-2052.

Beilstein, M. A. \& Whanger, P. D. (1986). Deposition of dietary organic and inorganic selenium in rat erythrocyte proteins. Journal of Nutrition 116, 1701-1710.

Bingham, S. A. \& Cummings, J. H. (1985). The use of creatinine output as a check on the completeness of 24hour urine collections. Human Nutrition: Clinical Nutrition 39C, 343-353.

Brown, M. W. \& Watkinson, J. H. (1977). An automated fluorimetric method for the determination of nanogram quantities of selenium. Analytica Chimica Acta 89, 29-35.

Burk, R. F. (1974). In vivo ${ }^{75} \mathrm{Se}$ binding to human plasma proteins after administration of ${ }^{75} \mathrm{SeO}_{3}^{2-}$. Biochimica et Biophysica Acta 372, 255-265.

Burk, R. F. (1976). Selenium in man. In Trace Elements in Human Health and Disease, vol. 2, pp. $105-133$. London: Academic Press.

Burk, R. F. (1986). Selenium and cancer: meaning of serum selenium levels. Journal of Nutrition 116, 1584 1586.

Butler, J. A., Thomson, C. D., Whanger, P. D. \& Robinson, M. F. (1991). Selenium distribution in blood fractions of New Zealand women taking organic or inorganic selenium. American Journal of Clinical Nutrition 53, 748-754. 
Clarke, J. T. (1961). Colorimetric determination and distribution of urinary creatinine and creatine. Clinical Chemistry 7, 271-283.

Janghorbani, M., Martin, R. F., Kasper, L. J., Sun, X. F. \& Young, V. R. (1990). The selenite-exchangeable metabolic pool in humans: a new concept for the assessment of selenium status. American Journal of Clinical Nutrition 51, 670-677.

Koushanpour, E. \& Kriz, W. (1986). Renal Physiology, 2nd ed. New York: Springer-Verlag.

Kraus, R. J., Foster, S. J. \& Ganther, H. E. (1985). Analysis of trimethylselenonium in urine by high performance liquid chromatography. Analytical Biochemistry 147, 432-436.

Levander, O. A., Alfthan, G., Arvilommi, H., Gref, G. C., Huttunen, J. K., Kataja, M. K., Koivistoinen, P. \& Pikkarainen, J. (1983). Bioavailability of selenium to Finnish men as assessed by platelet glutathione peroxidase activity and other blood parameters. American Journal of Clinical Nutrition 37, 887-897.

Levander, O. A. \& Burk, R. F. (1990). Selenium. In Present Knowledge of Nutrition, 6th ed., pp. 268-273 [M .L. Brown, editor]. Washington DC: ILSI, Nutrition Foundation.

Luo, X., Wei, H., Yang, C., Xing, J., Qiao, C., Feng, Y., Liu, J., Liu, Z., Wu, Q., Liu, Y., Stoecker, B J., Spallholz, J.E. \& Yang, S.P. (1985). Selenium intake and metabolic balance of 10 men from a low selenium area of China. American Journal of Clinical Nutrition 42, 31-37.

Meltzer, H. M., Norheim, G., Bibow, K., Myhre, K. \& Holm H. (1990). The form of selenium determines the response to supplementation in a selenium replete population. European Joumal of Clinical Nutrition 44, 497-508.

Meltzer, H. M., Norheim, G., Loken, E. B. \& Holm, H. (1992). Supplementation with wheat selenium induces a dose-dependent response in serum and urine of a Se-replete population. British Journal of Nutrition 67, $287-$ 294.

Mills, G. \& Hocken, A. G. (1986). Microalbuminuria in a diabetic population. New Zealand Medical Journal 99 , 17-19.

Nahapetian, A. T., Young, V. R. \& Janghorbani, M. (1984). Measurement of trimethylselenonium ion in human urine. Analytical Biochemistry 140, 56-62.

Oster, O. \& Prellwitz, W. (1990). The renal excretion of selenium. Biological Trace Element Research 24, 119 146.

Robberecht, H. J. \& Deelstra, H. A. (1984). Selenium in human urine: determination, speciation and concentration levels. Talanta 31, 497-508.

Robinson, J. R., Robinson, M. F., Levander, O. A. \& Thomson, C. D. (1985). Urinary excretion of selenium by New Zealand and North American human subjects on differing intakes. American Journal of Clinical Nutrition 41, 1023-1031.

Robinson, M. F. (1988). The New Zealand selenium experience. American Journal of Clinical Nutrition 48, 521-534.

Robinson, M. F., Jenkinson, C. P., Luzhen, G., Thomson, C. D. \& Whanger, P. D. (1989). Urinary excretion of selenium (Se) and trimethylselenonium (TMSe) by New Zealand women during long-term supplementation with selenate or selenomethionine (SeMet). In Selenium in Biology and Medicine, pp. 250-253 [A. Wendel, editor]. Heidelberg: Springer-Verlag.

Sandholm, M. (1973). The initial fate of a trace amount of intravenously administered selenite. Acta Pharmacologica et Toxicologica 33, 1-5.

Sun, X. A., Ting, B. T. G. \& Janghorbani, M. (1987). Excretion of trimethylselenonium ion in human urine. Analytical Biochemistry 167, 304-311.

Sunde, R. A. (1990). Molecular biology of selenoproteins. Annual Review of Nutrition 10, $451-474$.

Thomson, C. D., Burton, C. E. \& Robinson, M. F. (1978). On supplementing the selenium intake of New Zealanders: 1. Short experiments with large doses of selenite or selenomethionine. British Journal of Nutrition 39, 579-587.

Thomson, C. D., Ong, L. K. \& Robinson, M. F. (1985). Effects of supplementation with high-selenium wheat bread on selenium, glutathione peroxidase and related enzymes on blood components of New Zealand residents. American Joumal of Clinical Nutrition 41, 1015-1022.

Thomson, C. D. \& Robinson, M. F. (1986). Urinary and faecal excretions and absorption of a large supplement of selenium: superiority of selenate over selenite. American Journal of Clinical Nutrition 44, 659-663.

Thomson, C. D., Robinson, M. F., Butler, J. A. \& Whanger, P. D. (1993). Long-term supplementation with selenate and selenomethionine: selenium and glutathione peroxidasse (EC 1.11.1.9) in blood components of New Zealand women. British Journal of Nutrition 69, 577-588.

Thomson, C. D., Robinson, M. F., Campbell, D. R. \& Rea, H. M. (1982). Effect of a prolonged supplementation with daily supplements of selenomethionine and sodium selenite on glutathione peroxidase activity on blood of New Zealand residents. American Journal of Clinical Nutrition 36, $24-31$.

Thomson, C. D., Steven, S. M., Van Rij, A. M., Wade, C. R. \& Robinson, M. F. (1988). Selenium and vitamin E supplementation: activities of glutathione peroxidase in human tissue. American Journal of Clinical Nutrition 48, 316-323. 
Van Der Torre, H. W., Van Dokkum, W., Schaafsma, G., Wedel, M. \& Ockhuizen, T. (1991). Effect of various levels of selenium in wheat and meat on blood Se status indices and on Se balance in Dutch men. British Joumal of Nutrition 65, 69-80.

Varo, P., Alfthan, G., Ekholm, P., Aro, A.\& Koivistoinen, P. (1988). Selenium intake and serum selenium in Finland: effects of soil fertilization with selenium. American Journal of Clinical Nutrition 48, 324-329.

Webster, J. \& Garrow J. S. (1985). Creatinine excretion over 24 hours as a measure of body composition or of completeness of urine collection. Human Nutrition: Clinical Nutrition 39C, 101-106. 